\title{
PERANCANGAN ATS (AUTOMATIC TRANSFER SWITCH) SATU PHASA MENGGUNAKAN KONTROL BERBASIS RELAY DAN TIME DELAY RELAY (TDR)
}

\author{
Riki Rizaldi ${ }^{1}$, S.Umar Djufri ${ }^{2}$ \\ ${ }^{1}$ Jurusan Teknik Listrik, Fakultas Teknik, Universitas Batanghari \\ ${ }^{2}$ Dosen Teknik Listrik, Fakultas Teknik, Universitas Batanghari \\ e-mail: : rizaldiriki96@gmail.com, umarjufri@yahoo.com
}

\begin{abstract}
ABSTRAK
Pemadaman listrik dapat mengakibatkan terganggunya kontiunitas pelayanan terutama pada aktivitas pelayan pada sektor perdagangan, perhotelan, rumahsakit, maupun industri. Dewasa ini penyaluran energi listrik PLN sering terjadi kegagalan dalam pendistribusian dikarenakan faktor internal maupun faktor eksternal, untuk memenuhi kebutuhan kontiniunitas akan energi listrik maka diperlukan sumber energi listrik lain sehingga jika terjadi pemadaman listrik dari PLN kebutuhan konsumen akan energi listrik tidak terganggu. Sumber-sumber energi listrik ini bersifat sementara untuk melayani beban listrik dalam pemanfaatan energi listrik PLN menjadi sumber energi utama. ATS (Automatic Transfer switch), adalah alat yang berfungsi untuk memindahkan koneksi antara sumber tegangan listrik satu dengan sumber tegangan listrik lainnya secara automatis. Atau bisa juga disebut Automatic COS (Change Over Switch), pada penelitian ini akan dirancang sebuah ATS satu phasa dengan mereduksi jumlah Kontaktor untuk mendapatkan hasil yang lebih ekonomis dan mudah dalam perawatannya. ATS dalam penelitian ini menggunakan rangkaian kontrol berbasis relay dan Time Delay Relay $(T D R)$. Dari hasil pengujian, alat ini dapat bekerja dengan baik pada proses switching secara manual maupun secara otomatis. Pada saat PLN terjadi pemadaman, terdapat penundaan waktuselama \pm 6 detik sebelum genset melakukan starting. Hal ini bertujuan untuk menjaga komponen-komponen agar tidak rusak jika kadang kala PLN terjadi pemadaman sesaat.
\end{abstract}

Kata Kunci : ATS, Kontaktor, Genset, Timer

\section{PENDAHULUAN}

Peningkatan kebutuhan terhadap energi listrik pada kehidupan masyarakat Indonesia hampir tidak ada yang tidak membutuhkan energi listrik bahkan peningkatan kebutuhan tenaga listriknya tidak sebanding dengan peningkatan daya listrik.

Pemadaman listrik dapat mengakibatkan terganggunya kontiunitas pelayanan terutama pada aktivitas pelayan pada sektor perdagangan, perhotelan, rumahsakit, maupun industri.

Untuk mengatasi hal tersebut maka dirancang sebuah panel ATS satu phasa dengan komponen kontaktor, relay dan timer sehingga biaya produksi dapat dipangkas. ATS (Automatic Transfer switch), adalah alat yang berfungsi untuk memindahkan koneksi antara sumber tegangan listrik satu dengan sumber tegangan listrik lainnya secara automatis. Atau bisa juga disebut Automatic COS (Change Over Switch)

\section{TINJAUAN PUSTAKA}

\subsection{Automatic Transfer Switch}

Suatu alat pemindah (Transfer) sumber daya dari beban kesumber utama PLN ke Genset. Jika terjadi gangguan dari sumber utama yaitu PLN maka kontrol starting akan bekerja.

Berdasarkan rangkaian kontrolnya ATS dapat dibagi dua yaitu :

1. ATS yang menggunakan rangkaian kontrol PLC. 
2. ATS yang menggunakan rangkaian kontrol berbasis relay dan Time Delay Relay (TDR).

\subsection{PrinsipKerja ATS}

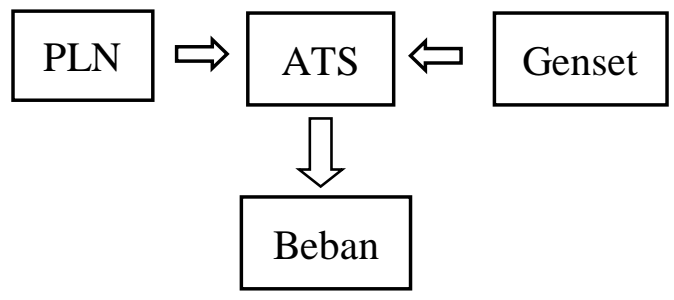

Gambar .1 Blok Diagram ATS[2]

Bilamana sumber PLN mengalami gangguan / pemadaman, dengan sistem yang telah dirancang maka genset pada sumber cadangan akan bekerja dan menggantikan sumber utama (PLN). Panel ATS ini dilengkapi dengan sistem keamanan dengan relay dan fuse. Sistem pengoperasian ini sangatlah mudah, karena telah diatur sedemikian rupa.

\subsection{Komponen Yang Digunakan}

\section{Relay MK2P 220VAC/VDC}

Relay terdiri dari koil dan kontak, bila koil mendapat energi listrik akan timbul gayae lektromagnetik yang akan menarik armature yang berpegas, kontak akan menutup sehingga dapat mengaliri arus.[4]

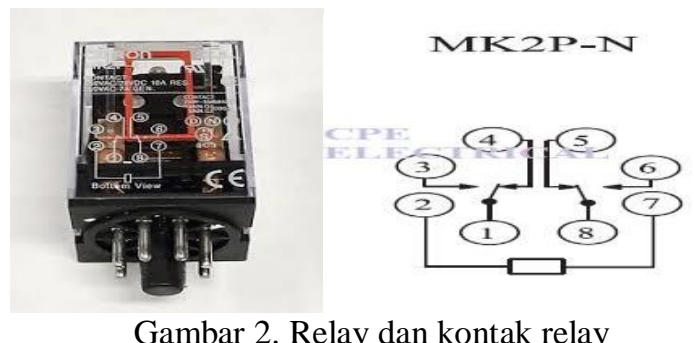

\section{Time Delay Relay (TDR) $220 \mathrm{~V}$}

Kumparan pada timer akan bekerja selama mendapat sumber arus. Apabila telah mencapai batas waktu yang diinginkan maka secara otomatis timer akan mengunci dan membuat $\mathrm{NO}$ menjadi NC dan kontak NC menjadi NO.

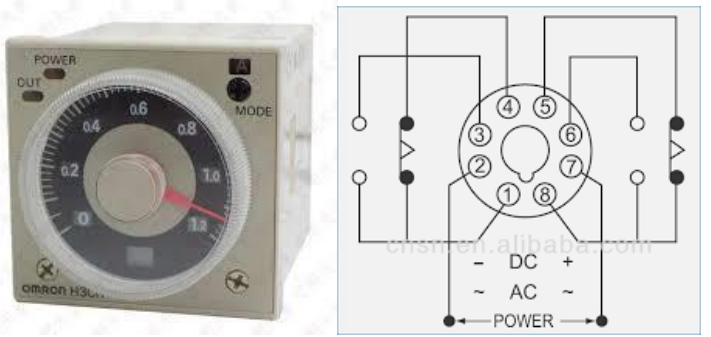

Gambar 3. Time Delay Relay 220V

\section{Magnetik Kontaktor}

Sebuah komponen yang berfungsi sebagai penghubung dengan kapasitas yang besar dengan menggunakan daya minimal.
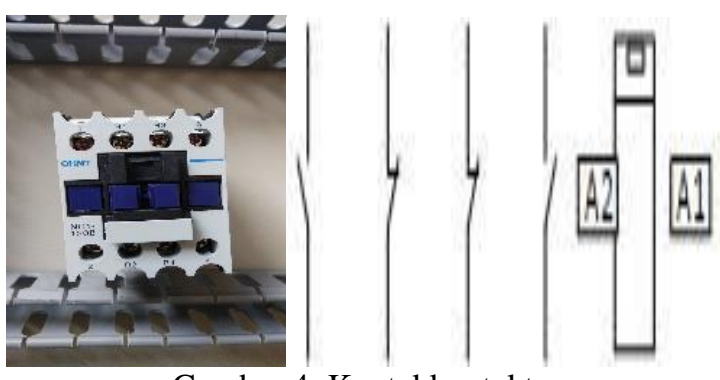

Gambar 4. Kontakkontaktor

\section{4. $\mathrm{MCB}$}

Alat pengaman yang berguna sebagai saklar dan pembatas arus listrik untuk mencegah terjadinya konsleting/hubung singkat akibat melonjaknya tegangan listrik.

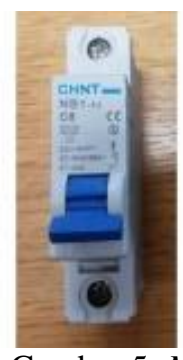

\section{Simbol MCB}

Gambar 5. Miniatur Circuit Breaker

\section{Main Auto Selector Switch}

Jika sistem bekerja secara manual, maka operator yang menentukan sumber daya listrik utama dari mana yang akan digunakan, sumber dari PLN atau dari genset. Namun jika sistem otomatis yang dipilih maka panel bekerja secara otomatis yang dikontrol oleh relay. 


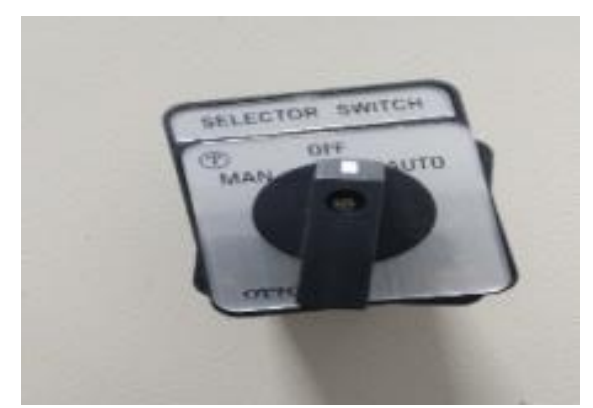

Gambar 6. Main Auto Selector Switch

\section{Terminal Block}

Suatu alat kelengkapan dalam sistem pengawatan yang fungsinya sebagai penghubung antar kabel. Kabel yang masuk dan keluar dari box panel harus melalui terminal ini.

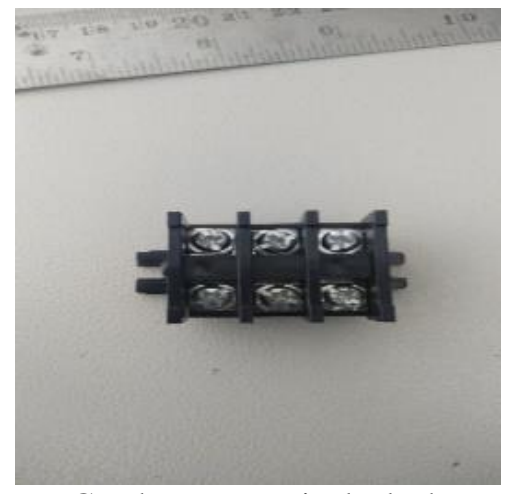

Gambar 7. Terminal Block

7. Panel

Box panel ini terdiri dari box utama untuk komponen-komponen yang dipasang di dalam dan pintu sebagai cover serta tempat interaksi dan pemantauan indikator.

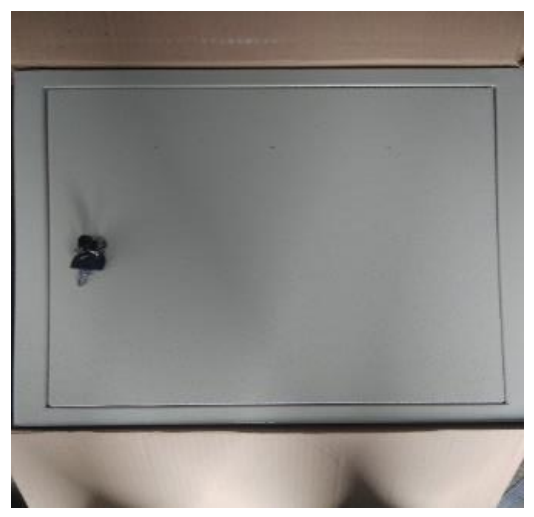

Gambar 8. Panel

\section{Lampu Indikator}

Lampu yang memberikan tanda atau isyarat apakah suatu rangkaian dalam keadaan beroperasi atau tidak.

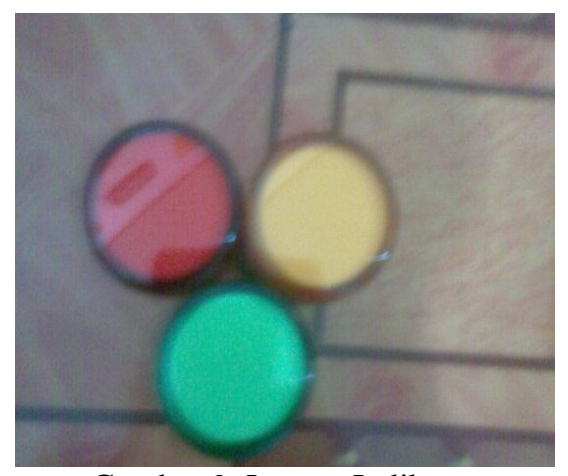

Gambar 9. Lampu Indikator

\subsection{Generator Set (Genset)}

Suatu generator listrik yang terdiri dari panel, berenergi solar dan terdapat kincir angin yang ditempatkan pada suatu tempat. Genset dapat digunakan sebagai sistem cadangan listrik atau "off-grid" (sumber daya yang tergantung atas kebutuhan pemakai).[2]

Selain itu, pemilihan generator juga harus memperhatikan keefektifan daya generator yang dipilih karena akan berhubungan dengan masalah investasi atau harga yang dikeluarkan.[2]

\subsection{Pengawatan Pada Panel ATS}

Kabel untuk pengawatan suatu panel harus dipilih dengan sedemikian rupa hingga penghantar tersebut mampu dialiri arus minimum $125 \%$ kali arus beban penuh. Dalam menentukan atau memilih kabel penghantar listrik harus diperhatikan dari segi kelistrikan sesuai dengan peraturan yang berlaku (PUIL). [5]

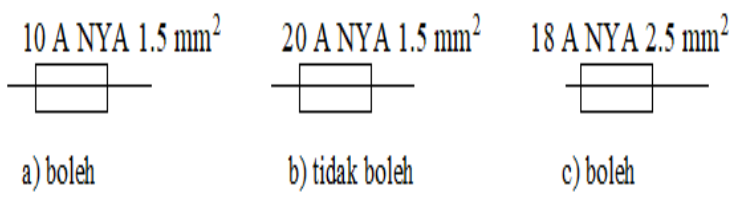

Gambar 10. Ketentuan kemmpuan kabel [5] 
3. METODE PENELITIAN

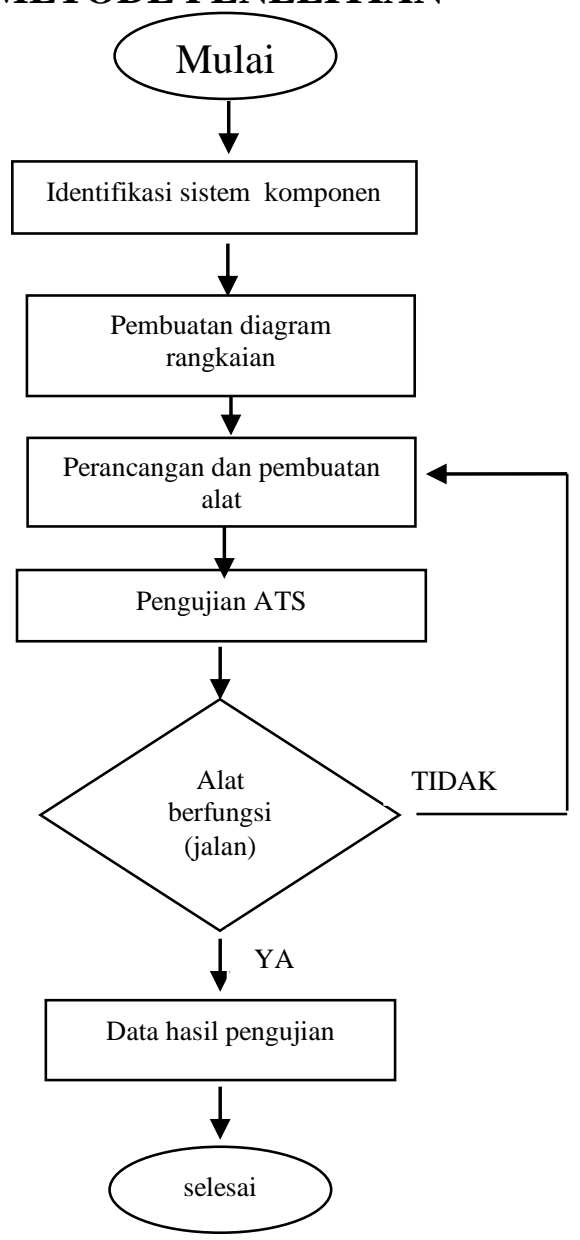

Gambar 11. Flowchart Penelitian

1. Mengidentifikasi Sistem Dan Komponen.

Mengidentifikasi sistem dan komponen yang akan digunakan dari mulai menghitung daya PLN dan daya Genset, karena itu menentukan komponen yang akan digunakan.

2. Pembuatan Diagram Rangkaian

Diagram rangkaian sangatlah penting sebelum memulai pekerjaan, dari diagram rangkaian kita dapat mengetahui alur pada rangakaian tersebut agar tidak terjadi kesalahan dalam pengerjaan.

3. Perancangan Dan Pembuatan Alat

Untuk memilih dan menentukan jenis peralatan atau komponen yang digunakan untuk membuat rangkaian kontrol Automatic Transfer Switch yang sederhana dengan biaya yang murah namun memiliki kemampuan yang baik dan sesuai dengan kapasitas beban yang dibutuhkan.

4. Pengujian ATS

Jika telah dilakukan pengujian maka bias diambil data hasil pengujian.

5. Alat berfungsi (jalan)

Apabila semua rangkaian telah benar dan bekerja dengan semestinya maka alat tersebut telah berfungsi, tapi apabila terjadi kesalahan pada rangkaian alat tidak akan bekerja maka, harus dilakukan pengecekkan kembali pada rangkaian tersebut.

6. Data Hasil Pengujian

Dapat diambil ketika alat bekerja dengan benar dan tidak terjadi lagi kesalahan.

\section{HASIL DAN PEMBAHASAN}

Pengujian ATS dilakukan berdasarkan dari wiring rangkaian yang direncanakan, kemudian seluruh alat yang disiapkan disusun kedalam box panel sehingga mudah dalam melakukan pengamatan sekaligus perawatan. adapun wiring diagram dari penelitian yang dilakukan seperti ditunjukan pada gambar 12 dibawah.

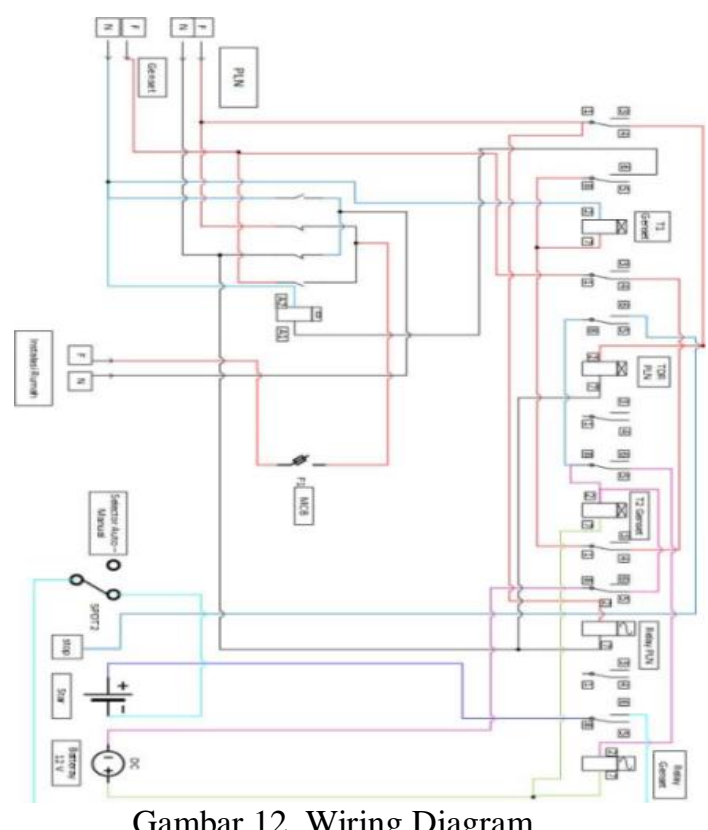

Pada saat star genset kontak relay genset mulai menstar genset secara Automatic serta kontak T2 genset untuk 
mengembali kanposisi awal kontak relay genset. Setelah selesai star (Genset On) tegangan belum langsung terhubung kebeban pada saat rungenset karena T1 genset akan bekerja menghantarkan tegangan kebeban setelah genset hidup, maka di atur waktu 7 detik untuk mengoperasikan K1 serta pemindahan sumber beban kesumber cadangan (Genset).

\subsection{Tata Letak Komponen}
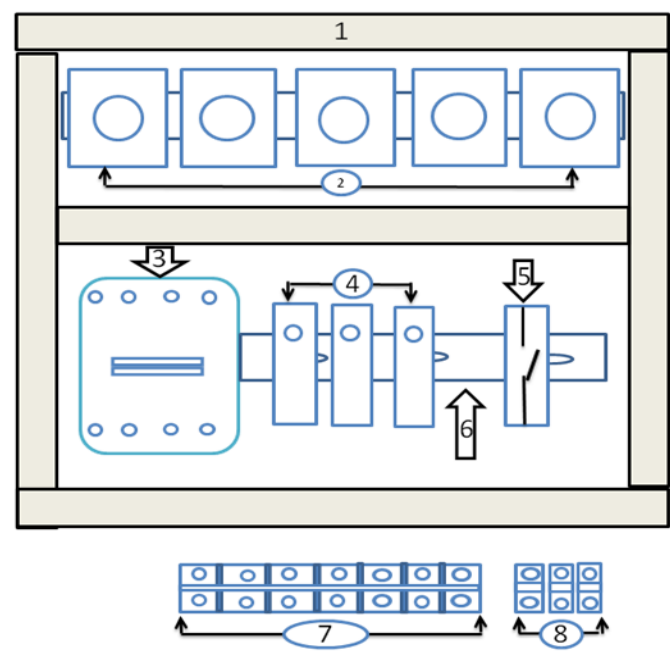

Gambar 13. Tata Letak Komponen

1. Ducting kabel

2. Time Delay Relay

3. Kontaktor

4. Fuse/Sekring

5. MCB

6. Rel

7. Terminal 6 pool $25 \mathrm{~A}$

8. Terminal kabel wiring

Adapun langkah pengerjaan yang dilakukan pada tata letak komponen didalam kotak panel adalah sebagai berikut:

1. Merancang Gambar

Merancang gambar rangkaian agar dapat diketahui alat dan bahan yang digunakan.

2. Pemasangan Duck

Pemasangan duct ini berguna untuk memudahkan dalam tahap perakitan kabel-kabel rangkaian.

3. Pemasangan Wiring Kabel
Pada tahap wiring ini harus diperhatikan bagaimana memilih jalur kabel agar kabel bisa hemat dan terlihat rapi.

4. Pemasangan Komponen.

Pemasangan komponen dilakukan sesuai dengan gambar rancangan dan alur wiring yang telah dibuat.

\subsection{Pengujian}

Pada penelitian ini Pengujian ATS dilakukan dengan menggunakan beban lampu (20 watt) dalam waktu timer $>20$ detik dan dalam waktu timer $<20$ detik.

1. Pengujian dalam waktu timer $>20$ detik Pada pengujian ini beban ATS menggunakan lampu dimana waktu timer di setting > 20 detik, hasil dari pengujian diperlihatkan pada tabel 1 dibawah.

Tabel 1. Data Pengujian Setting > 20 Detik

\begin{tabular}{|c|c|c|c|c|c|c|}
\hline \multirow{2}{*}{$\begin{array}{c}\text { Pengujian } \\
\text { ke - }\end{array}$} & \multirow{2}{*}{$\begin{array}{l}\text { Tegangan } \\
\text { PLN (volt) }\end{array}$} & \multicolumn{2}{|c|}{ Kondisi kontaktor } & \multirow{2}{*}{$\begin{array}{c}\text { Kondisi } \\
\text { beban }\end{array}$} & \multirow{2}{*}{$\mathrm{t}$ (detik) } & \multirow{2}{*}{$\begin{array}{c}\text { Tegangan } \\
\text { Genset (volt', }\end{array}$} \\
\hline & & PLN & Genset & & & \\
\hline \multirow{4}{*}{1} & Ada & $\mathrm{ON}$ & OFF & ON & - & \\
\hline & Tidak ada & OFF & OFF & OFF & - & \\
\hline & Tidak ada & OFF & ON & ON & 25 & 222 \\
\hline & Ada & ON & OFF & ON & - & \\
\hline \multirow{4}{*}{2} & Ada & ON & OFF & ON & - & \\
\hline & Tidak ada & OFF & OFF & OFF & - & \\
\hline & Tidak ada & OFF & ON & ON & 27 & 222 \\
\hline & Ada & ON & OFF & ON & - & \\
\hline \multirow{4}{*}{3} & Ada & ON & OFF & ON & - & \\
\hline & Tidak ada & OFF & OFF & OFF & - & \\
\hline & Tidak ada & OFF & ON & ON & 30 & 222 \\
\hline & Ada & $\mathrm{ON}$ & OFF & ON & - & \\
\hline \multirow{4}{*}{4} & Ada & ON & OFF & ON & - & \\
\hline & Tidak ada & OFF & OFF & OFF & - & \\
\hline & lidak ada & $\mathrm{OHF}$ & ON & ON & 35 & 222 \\
\hline & Ada & ON & OFF & ON & - & \\
\hline
\end{tabular}

2. Pengujian dalam waktu timer $<20$ detik Pada pengujian ini beban ATS menggunakan lampu dimana waktu timer di setting $<20$ detik, hasil pengujian diperlihatkan pada tabel 2 . dibawah 
Tabel 2. Data Pengujian Setting < 20 Detik

\begin{tabular}{|c|c|c|c|c|c|c|}
\hline \multirow{2}{*}{$\begin{array}{c}\text { Pengujian } \\
\text { ke - }\end{array}$} & \multirow{2}{*}{$\begin{array}{l}\text { Tegangan } \\
\text { PLN (volt) }\end{array}$} & \multicolumn{2}{|c|}{ Kondisi kontaktor } & \multirow{2}{*}{$\begin{array}{l}\text { Kondisi } \\
\text { beban }\end{array}$} & \multirow{2}{*}{$t$ (detik) } & \multirow{2}{*}{$\begin{array}{c}\text { Tegangan } \\
\text { Genset (volt) }\end{array}$} \\
\hline & & PLN & Genset & & & \\
\hline \multirow{4}{*}{1} & Ada & $\mathrm{ON}$ & OFF & $\mathrm{ON}$ & - & - \\
\hline & Tidak ada & OFF & OFF & OFF & - & - \\
\hline & Tidak ada & OFF & $\mathrm{ON}$ & $\mathrm{ON}$ & 5 & 215 \\
\hline & Ada & ON & $\mathrm{OFF}$ & $\mathrm{ON}$ & - & - \\
\hline \multirow{4}{*}{2} & Ada & $\mathrm{ON}$ & OFF & $\mathrm{ON}$ & - & - \\
\hline & Tidak ada & OFF & OFF & OFF & - & - \\
\hline & Tidak ada & OFF & $\mathrm{ON}$ & $\mathrm{ON}$ & 7 & 220 \\
\hline & Ada & $\mathrm{ON}$ & $\mathrm{OFF}$ & $\mathrm{ON}$ & - & - \\
\hline \multirow{4}{*}{3} & Ada & $\mathrm{ON}$ & OFF & $\mathrm{ON}$ & - & - \\
\hline & Tidak ada & OFF & $\mathrm{OFF}$ & OFF & - & - \\
\hline & Tidak ada & OFF & $\mathrm{ON}$ & $\mathrm{ON}$ & 10 & 221 \\
\hline & Ada & $\mathrm{ON}$ & OFF & $\mathrm{ON}$ & - & - \\
\hline \multirow{4}{*}{4} & Ada & $\mathrm{ON}$ & OFF & $\mathrm{ON}$ & - & - \\
\hline & Tidak ada & OFF & $\mathrm{OFF}$ & OFF & - & - \\
\hline & Tidak ada & OFF & $\mathrm{ON}$ & $\mathrm{ON}$ & 15 & 222 \\
\hline & Ada & $\mathrm{ON}$ & $\mathrm{OFF}$ & $\mathrm{ON}$ & - & \\
\hline
\end{tabular}

\section{SIMPULAN}

a. Masukan data untuk ATS berupa nilai tegangan sumber listrik PLN yang dideteksi oleh sensor tegangan.

b. Penggunaan ATS dikhususkan pada genset yang memiliki elektrik starter.

c. Alat dapat bekerja dengan baik pada proses switching secara manual maupun secaraotomatis.

d. Pada saat PLN terjadi pemadaman, terdapat penundaan waktu selama \pm 6 detik sebelum genset melakukan starting. Hal ini bertujuan untuk menjaga komponen-komponen agar tidak rusak jika kadang kala PLN terjadi pemadaman sesaat.

e. Dari data yang diambil ATS bisa bekerja dengan baik sesuai dengan perancangan sistem kerja yakni ATS melakukan proses switching dari sumber listrik PLN ke genset dalam $\mathrm{t}>20$ detik,

\section{DAFTAR PUSTAKA}

[1] D. Hendarto, Rozali 2015. Rancang Bangun Panel Automatic Transfer Switch( Ats ) Dan Automatic Main Failure ( Amf ) Kapasitas 66 Kva.Teknik Elektro Fakultas Teknik Universitas Ibn Khaldun Bogor. Hlm
21-32. Bogor

[2] A. Alfith, 2017. Optimalsasi ATS (Automatic Transfer Switch) pada Genset (Generator Set) 2800 Watt Berbasis TDR.Institut Teknologi Padang. Hlm 226-232. Padang

[3] A. B. Bimo, H. Santoso. 2007. Rancang Bangun Automatic Transfer Switch.J. EECCIS, vol. 1, no. 1, hlm. 1-6.

[4] E. Susanto. 2013. Automatic Transfer Switch (Suatu Tinjauan).Teknik Elektro Universitas Negeri Semarang, vol. 5 no. 1, hlm. 18-21. Semarang

[5] Puil 2000. Persyaratan Umum Instalasi Listrik. 